\title{
Mesa Nacional de Educación Rural. Un escenario para pensar la educación en territorios rurales de Colombia
}

\author{
¿Cómo puede la educación contribuir a que el campo \\ sea una opción de vida con bienestar y dignidad? \\ $\mathrm{Y}$ ¿cuáles son sus alcances? \\ ¿De qué articulaciones e integraciones hablamos? \\ ¿Qué políticas e instituciones son necesarias?
}

Los autores

Una vez celebrado el Cuarto Congreso Nacional de Educación Rural en Bogotá, en 2016, se insistió en acoger las conclusiones a las que se había llegado en las plenarias finales de los congresos anteriores (Manizales, 2004; Villavicencio, 2007; Medellín, 2010) y avanzar en los compromisos y las acciones que requieren algunas de sus reflexiones:

1. Existen pocos espacios de debate, reflexión y construcción para los asuntos de la educación de la Población Rural Colombiana, donde se socialicen experiencias, innovaciones y perspectivas para abordar los conflictos del sector educativo y aportar a los demás fenómenos que afectan directa e indirectamente las poblaciones campesinas. El diálogo ha sido quizás uno de los principales déficits sociales de la comunidad latinoamericana y en particular de la sociedad colombiana, que le ha apostado mayoritariamente a la resolución de conflictos por vías más rápidas, pero finalmente poco efectivas. Las decisiones tomadas desde criterios ajenos a las realidades de los territorios se transforman en resultados de bajo impacto y fomentan la cultura de la "dependencia", haciendo cada vez más difícil el proceso de construcción colectiva, con participación de todos los sectores de sociedad, principalmente las comunidades para las cuales se propone un proyecto educativo. Los talleres, seminarios, foros, congresos, conferencias y todas aquellas metodologías que convoquen el encuentro de personas e instituciones que comparten un propósito común es una valiosa alternativa para fomentar el "diálogo" y con ello la "pertinencia" de los impactos que se demandan.

2. Desde la premisa del mundo globalizado, la idea de desarrollo prima sobre otras formas de vida e impone un "progreso" desigual entre las regiones colombianas, siendo las zonas rurales aisladas las más relegadas, en donde son notorias las carencias en términos de formación del talento humano, infraestructura, servicios, actividades empresariales (lo que se impone es la explotación minera deja a los territorios con grandes afectaciones ambientales). Este desarrollo favorece a las grandes elites, perjudica la consolidación de los territorios y es caldo de cultivo para la continuación del endémico conflicto colombiano. 
3. En indicadores sociales existen mayores carencias en las zonas rurales. Aspectos como el acceso a la educación, la salud, el empleo, la tecnología, parten de los bajos niveles de los procesos formativos, la débil permanencia en el acompañamiento institucional y la poca o nula existencia de proyectos educativos formulados desde las apuestas de vida de las comunidades.

4. Es completamente visible la falta de planeación de la educación rural en los territorios y la desarticulación entre estos y las perspectivas de las autoridades educativas de las regiones, en contraste con las necesidades e intereses de las organizaciones comunitarias.

5. La fusión de la institución escolar (Ley 715 del 2001) puso a depender la escuela veredal de las sedes de secundaria ubicadas en las cabeceras municipales, lo cual no se ha traducido en mejoramiento de los procesos pedagógicos y de gestión. Esto, por el contrario, está afectando la estrecha relación comunidad "veredal-escuela", que ha sido el eje del funcionamiento de la educación rural.

6. La educación técnica en las instituciones rurales, en su gran mayoría, está descontextualizada de las vocaciones productivas de los territorios y no tiene relación con los sectores empresariales productivos rurales, incluso choca con ideas alternativas al desarrollo propias de los pueblos. En este sentido no aporta al desarrollo regional y a la construcción social de territorios.

7. Actualmente se valora la existencia de diferentes modelos flexibles en la educación rural colombiana que han procurado acompañar y prestar el servicio a las poblaciones campesinas, lo que constituye un significativo aporte pedagógico a la educación en general. Sin embargo, estos modelos requieren de procesos permanentes de investigación, sistematización y actualización, así como de la incorporación estructural a la política y al sistema de educación rural nacional.

8. Es necesario hacer efectivas las recomendaciones presentadas por los informes de las misiones rurales y de los informes de desarrollo humano en Colombia.

Unido a todo lo anterior, la permanencia y continuidad del servicio educativo en la ruralidad requiere una revisión al actual sistema de cobertura que no ofrece garantías y que adolece de una planificación estratégica para las cuatro dimensiones que Naciones Unidas acogió como dimensiones del derecho a la educación: a. Una obligación de asequibilidad, también conocida como de disponibilidad, que implica satisfacer la demanda educativa ya sea por la oferta pública o la protección de la oferta privada. Ello supone la doble obligación de establecer o financiar instituciones educativas y de abstenerse de prohibir a los particulares la fundación de instituciones educativas.

b. Una obligación de accesibilidad, según la cual el Estado se compromete a garantizar el acceso a las escuelas públicas disponibles sin discriminación alguna.

c. Una obligación de aceptabilidad, conforme a la cual el Estado debe asegurar la adecuada calidad de la educación.

d. Una obligación de adaptabilidad, por la cual los Estados tienen la obligación de brindar en sus centros educativos la educación que mejor se adapte a las poblaciones.

El cuarto congreso ratifico que es fundamental "Contribuir al mejoramiento de la educación y el desarrollo rural en Colombia a través de un espacio de reflexión y construcción permanente entre los diferentes actores y sectores de la sociedad civil y el Estado, para generar alternativas que fortalezcan la identidad local y la incidencia en política pública educativa para un mundo globalizado" (Congreso Nacional de Educación Rural, 2010, p. 8). Este congreso permitió concluir que:

existe una crisis generalizada que rodea el desarrollo de las naciones y una tensión fuerte que rodea la economía mundial, donde la territorialidad rural y los recursos naturales son objeto de disputa entre persistir en el modo de producción para la acumulación de capitales o producir para la satisfacción de necesidades fundamentales en el marco del desarrollo a escala humana o incluso apuntar a la idea de alternativas al desarrollo o buen vivir. Esto último demanda necesariamente una política de Estado soportada en los derechos humanos, en la conservación de los ecosistemas y en los tratados internacionales que aspiran a la convivencia pacífica entre los seres humanos y los territorios que habitan. (Congreso Nacional de Educación Rural, 2010, p. 8).

Al revisar los estudios y análisis que se han realizado sobre la educación rural en particular y la ruralidad colombiana en general, nos encontramos con insumos 
importantes que bien valdría la pena retomar para la formulación de apuestas políticas pensadas para el contexto rural. Estamos hablando de investigaciones como la Misión Rural y su informe final "Colombia en transición-1998"; el informe de la Comisión de Sabios "Colombia al filo de la oportunidad-1996"; diagnósticos de Unesco y Cepal; el informe sobre el disfrute del derecho a la educación en Colombia de Naciones Unidas; el estudio sobre la educación para la población rural en Colombia liderado por la FAO, Unesco y otros; y por último, los informes consecutivos de desarrollo humano del PNUD 2010 y 2011, este último presentado en el informe final titulado "Colombia rural: razones para la esperanza". Algunos de sus resultados no solo han respondido a diagnosticar la realidad rural, sino que los investigadores han señalado los componentes que podrían transformar dichas realidades en factores positivos de vida digna en la ruralidad.

Así mismo, podemos mencionar otros aspectos importantes que resaltan dichos estudios y que deben tenerse en cuenta al momento de tomar decisiones en materia de política pública rural:

- Del informe "Colombia rural: razones para la esperanza":

Colombia es más rural de lo que pensamos. Pero por casi cuarenta años, la progresión del proceso de urbanización como la ruta privilegiada hacia la modernización opacó esa realidad. No el 25 sino el 32\% de los colombianos son pobladores rurales, y en las tres cuartas partes de los municipios, cuya área ocupa la mayoría del territorio nacional, predominan relaciones propias de sociedades rurales. (PNUD, 2011, p. 7).

- En otro aparte dicho informe comenta:

Uno de los hallazgos más importantes del Informe es que el campesinado no ha logrado que el Estado reconozca su importancia como grupo social, a lo que se ha sumado la victimización histórica a la que ha sido condenado por la violencia. Existe una "falla de reconocimiento" es decir, una falta de valoración de un sujeto particular para dar paso a sus derechos y constitución de ciudadanía". (PNUD, 2011, p. 63)
- Desde las conclusiones de los Foros de Educación Veredal realizados en el departamento de Antioquia 2013 y 2014 se hace el pedido para pensar y considerar el tipo de acciones que se asumen para las poblaciones rurales:

Deben priorizarse las reflexiones sobre el entorno rural y la mejora de las condiciones del campesinado como individuos y como colectivos en múltiples dimensiones como los procesos de liderazgo productivo (economía), procesos de participación, intervención e interacción (política), construcciones inter e intra grupos sociales (interculturalidad y espiritualidad), relaciones con la naturaleza (ecología), todo ello enmarcado en los procesos de educación y constitución del estado colombiano.

Con estos y otros propósitos, se instala la Mesa Nacional de Educación Rural, como espacio de reflexión permanente, de construcción de conocimiento, de movilización pedagógica en la ruralidad, de impulso a nuevas iniciativas e institucionalidades, para posibilitar las acciones necesarias que contribuyan a la paz estable y duradera y a la no repetición del conflicto armado. Ello solo será posible con acciones consistentes, duraderas y en el marco del respeto a los planes de vida de las poblaciones rurales y los planes de vida de sus territorios. Dos conceptos serán fundamentales para la dimensión de la política de educación rural: el concepto de educación y pedagogía rural y el concepto de desarrollo rural. Estas dos construcciones darán en cierta forma el rumbo que tomen los planes, programas y proyectos para las poblaciones y los territorios rurales.

Sea cual sea la construcción que se defina tendrá que contener tres intencionalidades: primera, la cohesión social como poder político y público de las poblaciones campesinas, indígenas o afrodescendientes según el caso; segunda, la formación de sujetos e instituciones éticas y solidarias; tercera, sociedades rurales y territorios en la perspectiva del bienestar y la vida digna.

Un último elemento que recoge de alguna manera los expuestos tiene que ver con las formas de ser maestro y el lugar de la pedagogía en los territorios; es justamente en esta intencionalidad donde la presencia de la Universidad Pedagógica Nacional cobra sentido en la Mesa de Educación Rural, en tanto que es fundamental 
aportar a unas pedagogías para lo rural y el "sentipensar" de los maestros y maestras que contribuyan desde la educación a otras formas de relacionamiento, de construcción de conocimiento que aporten a los cambios en la producción, la participación, el diálogo cultural, el reconocimiento de los saberes circundantes en los territorios nacionales rurales.

Estos cambios no podrán lograrse sino con el concurso de maestros y maestras rurales, a partir de la lectura juiciosa del país desde las narrativas y voces de los actores en cada región, que permita la circulación de saberes en pro de la reconstrucción social impulsando una educación al servicio de los proyectos de vida de las comunidades. Por ello, la mesa invita a la participación activa de los educadores desde las diferentes instituciones (publicas, privadas, comunitarias, de educación propia, etc.) desde la experiencia construida como docentes rurales. Este aporte se pretende consolidar en la creación de una red de maestros rurales en todo el territorio nacional, donde se recogerá la memoria de su hacer desde la particularidades de una ruralidad diversa.

Así mismo esperamos la integración de todas y todos aquellos que sueñen y deseen trabajar por una educación en pro de los proyectos de vida de nuestros territorios rurales, a contribuir a la consolidación de mesas regionales, donde se espera vincular el saber constituido desde las distintas formas y prácticas en las que circule el conocimiento en sus diversas comunidades. Estas mesas son la voz de la diversidad territorial, en ellas se discuten los asuntos propios de cada región que luego son expuestos en la mesa nacional por un representante elegido en cada mesa regional.

Las mesas se visualizan como escenarios de trabajo colectivo, en las que el reconocimiento de la diversidad rural permita el diálogo de saberes, la interculturalidad y la construcción de una propuesta de educación rural desde y para los pueblos. Hasta el momento se encuentran en proceso de instalación las mesas de: regional Caribe, Arauca, Tolima, Santander, Boyacá, Cundinamarca, Antioquia, Eje cafetero y Bogotá. Vale la pena señalar que estos procesos de instalación son permanentes en tanto pueden irse sumando al trabajo de las mismas en diferentes momentos. En este proceso de consolidación han venido surgiendo otros intereses respecto a temas o poblaciones particulares: es el caso de las mujeres, los jóvenes y la primera infancia, quienes al interior de las mesas regionales y la maesa nacional, construyen agendas propias que van enriqueciendo desde el diálogo y la concertación.

Así, la mesa se consolida como un movimiento social que pretende tener alcance nacional; para ello, la invitación importante que se hace a todas aquellas regiones que están fuera del radar consiste en establecer vínculos, manifestar el interés de estar y desde allí poder encaminar acciones que nos permitan impulsar la consolidación de sus mesas regionales.

Solo con la participación activa del país rural desde sus particularidades podremos pensar en una educación digna y al servicio de los pueblos; entonces, podremos ver la viabilidad de aquella afirmación "ser campesino debe ser una opción de vida con identidad, calidad, seguridad integral y con acceso a las oportunidades del verdadero desarrollo".

No puede haber transformación social sin educación, pero con la sola educación no es suficiente.

Los autores

Jorge Hernán Marín Maya Corporación La Ceiba, Institución asociada a Coreducar nacional

Adriana Patricia Mendoza Báez Docente Investigadora Universidad Pedagógica Nacional Participantes de la Mesa Nacional de Educación Rural

Contáctanos en:

http://www.congresoeducacionruralcoreducar.com/ comunicaciones@congresoeducacionruralcoreducar.com

\section{Referencias}

Congreso Nacional de Educación Rural. (2010). Conclusiones y propuestas, III Congreso Nacional de Educación Rural, MedeIlín, 8, 9 y 10 de julio de 2010. Recuperado de http://www. icproc.org.co/administrador/repositorio/file/memorias_3er_congreso_nal_educacion_rural.pdf

PNUD. (2011). Colombia rural. Razones para la esperanza. Resumen ejecutivo. Informe Nacional de Desarrollo Humano 2011. Bogotá: INDH, PNUD. Recuperado de http://hdr.undp.org/ sites/default/files/nhdr_colombia_2011_es_resumen_low.pdf 